\title{
EFFECT OF LATERAL EARTH RESISTIVITY CHANGES ON EARTH SURFACE POTENTIAL AROUND DC GROUNDING ELECTRODES
}

\author{
MA, C. ${ }^{1,3^{*}}-$ LIU, L. $^{1}-$ SUN, L. $^{2}-$ ZHAO, S. ${ }^{2}$ \\ ${ }^{1}$ State Key Laboratory of Alternate Electrical Power System With Renewable Energy Sources \\ (North China Electric Power University), Changping District, Beijing 102206, China \\ (e-mail: alian0220224@163.com-L.Liu) \\ ${ }^{2}$ School of Electrical Engineering, Northeast Electric Power University, Jilin 132012, Jilin, China \\ (e-mails: sunlinedu@163.com-L.Sun,649425903@qq.com-S. Zhao) \\ ${ }^{3}$ School of Electrical and Electronic Engineering, North China Electric Power University, Beijing, \\ China \\ *Corresponding author \\ e-mail: machenglian@neepu.edu.cn \\ (Received $8^{\text {th }}$ Mar 2019; accepted $21^{\text {st }}$ May 2019)
}

\begin{abstract}
In the trial stage of Xiluodu-Zhexi $\pm 800 \mathrm{kV}$ HVDC project, grounding current trough DC electrode incurred severe DC bias in substation transformers near the Jinsi electrode, indicating further research on the factors influencing such DC bias problem and since vertical and lateral change of soli resistivity could be one of the main factors, their mechanisms should be studied. Besides a normal layered earth resistivity model, a complex model was established to simulate forms of lateral resistivity changes according to measured soil resistivity data at the site of Jinsi electrode. Then ESP was calculated with finite element method and the effect of lateral change on ESP and its characteristics was analyzed. Later, an assumed case example demonstrated the error of DC bias estimation caused by such ESP distortion. The results suggest the distance from DC electrode to the lateral change interface influences ESP distortion the most, and a high resistivity region in shallow layers at $5 \mathrm{~km}$ from DC electrode could incur a relative error of $25.9 \%$ in DC bias estimation. The grounding location and impact assessment has indicated that the measurement range of the earth resistivity should be investigated.
\end{abstract}

Keywords: DC bias, mechanisms, finite element method, converter station, transformer substation

\section{Introduction}

In the trial stage of XiluoduWestern Zhejiang $\pm 800 \mathrm{kV}$ High Voltage Direct Current (HVDC) project, grounding current trough Direct Current (DC) electrode incurred severe DC bias in substation transformers near Jinsi electrode (Yang et al., 2018). During the trial stage of March 28, 2014, the measured DC bias current of some transformer neutral point is more than $10 \mathrm{~A}$ while the grounding current of the grounding electrode is only 500 A (Kazerooni et al., 2016a; Wali et al., 2018). According to the rated transmission power XiluoduWestern Zhejiang $\pm 800 \mathrm{kV}$ HVDC project, the grounding current of the grounding electrode can reach 5000 A during full load operation with single pole. Due to the transformer DC bias current is linear with the ground current, the 5000 A ground current will produce 100200 A DC bias current in the substation transformer near the grounding electrode, which may threat the safety of the power system and transformer (Kang et al., 2018). Although a large number of DC transmission projects have been successfully constructed and put into operation, the problem of DC bias in XiluoduWestern Zhejiang Ultra High Voltage Direct Current 
(UHVDC) Project shows that the influence factors and mechanism of DC bias have not been fully understood in the study of grounding electrode effect.

The influence assessment of grounding electrode on DC bias of transformer is based on the establishment of power grid model, Earth resistivity model, and the network topology. The accuracy of the former depends on power grid parameters. The latter depends on the mastery of the stratified data of the earth's resistivity and the differential data of the transverse and longitudinal directions. The problem belongs to the geodetic and geodetic problems in the field of Geophysics (Mousavi and Bonmann, 2017; Kazerooni et al., 2016b; Austin et al., 2018). In the grounding location selection and its impact assessment of HVDC and UHVDC, selection and design of grounding electrode are only based on the comprehensive calculation of the earth resistivity from several dozens of measuring points near the electrode. The ground potential is calculated by horizontal homogeneous layered earth resistivity model with the measured data of ground resistivity. The influence of grounding electrode current on the dc bias of transformer is evaluated. The influence of the lateral variation factors of the earth resistivity is not considered. Compared with uniform distribution of the earth resistivity, the research result of geomagnetic storm induced electric field shows that within $1000 \mathrm{~km}$ around the earth resistivity lateral variation interface, the surface potential always changes. When the change frequency of geomagnetic storm surface current is $0.03 \mathrm{~Hz}$, the electric field increases at $70 \%$ near the low conduction proximity interface (Hussein and Ali, 2017; Arslan et al., 2018). Compared with the influence of geomagnetic storms, geomagnetic storms have greater impact scale and mainly consider the distribution of geoelectric field along the transmission line. Although the effect of DC grounding electrode current is relatively small, usually in the range of $100 \mathrm{~km}$, it is necessary to consider the potential distribution of the circular area with the earth electrode as the center. In theory, the grounding electrode current penetrates the earth deeper, and the lithosphere structure of China is the most complicated in the world (Choi et al., 2018; Moon et al., 2017; Liu and Liu, 2017; Wang et al., 2015; Okpoli and Ehinmitan, 2019). Therefore, in the site selection and impact assessment of ground electrode, it is very complicated to clarify the influencing factors and mechanism of the electrode site resistivity.

Whether the serious DC bias problem in Xiluodu-western Zhejiang UHVDC Project is influenced by the earth structure around the Jinsi electrode, or the resistivity of the deep earth, due to the lack of detailed magnetotelluric data of the earth, there is no inference at present. However, the test report on soil resistivity of Jinsi electrode in Xiluodu-western Zhejiang UHVDC Project shows that, the soil structure of electrode surrounding and the horizontal uniformity of shallow soil has a great influence on the surface potential distribution. The related papers are also discussed (Wei-Li and Liu, 2013). In this paper, according to the test data of soil resistivity in the site selection and design of Jinsi grounding electrode, and the types of lateral variation of soil resistivity reported in the test report, the earth resistivity model and surface potential algorithm considering lateral variation of earth resistivity are established (Zhou et al., 2016; Kasim et al., 2019). The influence of the width, depth, resistivity, distance from interface to ground electrode on the surface potential distribution around the electrode site and its characteristics are studied. According to the influence characteristics, the mechanism of serious DC bias caused by Jinsi grounding electrode is revealed, which provides basis for site selection of UHVDC grounding electrode and resistivity test scheme. 
According to the earth resistivity data near the Jinsi grounding electrode of XiluoduWestern Zhejiang UHVDC project, based on the lateral variation of the resistivity between the faults in the soil structure and the shallow-layer resistance, a model of the earth resistivity considering lateral variation is proposed. The surface potential distribution near grounding electrode is calculated by finite element method. The influence of lateral variation on surface potential distribution and its characteristics are compared and analyzed with different soil parameters. The error of the DC bias current caused by the change of the uneven potential distribution of the earth's transverse resistivity distribution is analyzed with an example. The conclusions provide a theoretical reference for accurate estimation of DC bias level and site selection of grounding electrode in practical engineering.

\section{Materials and methods}

\section{Horizontal homogeneous layered earth resistivity model}

Earth resistivity of Jinsi grounding electrode is obtained by 87 measuring points near the electrode with conventional symmetrical quadrupole method, 4 measuring lines of Controlled Source Audiofrequency Magnetotelluric (CSAMT) and 3 measuring points of Magnetic Tube (MT). Based on the 6 layer earth resistivity model, a horizontal homogeneous layered earth resistivity model is proposed and shown in Figure 1, and the parameters of each layer are shown in Table 1.

\begin{tabular}{|c|c|c|}
\hline$\rho_{1}$ & $\mathrm{~h}_{1}$ & \\
\hline$\rho_{2}$ & $\mathrm{~h}_{2}$ & \\
\hline$\rho_{3}$ & $\mathrm{~h}_{3}$ & \\
\hline$\rho_{4}$ & $\mathrm{~h}_{4}$ & \\
\hline$\rho_{5}$ & $\mathrm{~h}_{5}$ & \\
\hline
\end{tabular}

Figure 1. Layered earth resistivity model

Table 1. Parameters of layered earth resistivity around electrode

\begin{tabular}{c|c|c}
\hline Layer & Depth $(\mathbf{m})$ & Resistivity $(\mathbf{\Omega} \cdot \mathbf{m})$ \\
\hline 1 & $0-45$ & 50 \\
2 & $45-155$ & 250 \\
3 & $155-300$ & 2500 \\
4 & $300-600$ & 400 \\
5 & $600-2000$ & 1500 \\
6 & $>2000$ & 4000 \\
\hline
\end{tabular}

\section{A composite model considering the lateral variation of earth resistivity}

The above horizontal homogeneous earth resistivity model is a common model for the calculation of surface potential at present. The earth resistivity test of Jinsi electrode 
covers only $1 \mathrm{~km}^{2}$ range, and the results of some measurement points reflect the earth fracture and high and low resistance mixed in this area. To study the influence of the lateral variation of the earth resistivity on the surface potential of ground electrode (Liu et al., 2018; Rajput et al., 2019), a composite geodetic resistivity model considering lateral variation based on the type of horizontal change reflected by the resistivity test has been proposed and shown in Figure 2.

\begin{tabular}{cc|c|c} 
ground electrode site & \multicolumn{1}{c|}{$\mathbf{D}$} & $\mathbf{L}$ & \\
\hline$\rho_{1}$ & $\mathbf{h}_{1}$ & $\rho_{1 \mathrm{r}}$ & \\
\hline$\rho_{2}$ & $\mathbf{h}_{2}$ & $\rho_{2 \mathrm{r}}$ & $\rho_{1}$ \\
\hline$\rho_{3}$ & $\mathbf{h}_{3}$ & $\rho_{3 \mathrm{r}}$ & $\rho_{2}$ \\
\hline$\rho_{4}$ & $\mathbf{h}_{4}$ & $\rho_{4 \mathrm{r}}$ & $\rho_{3}$ \\
\hline$\rho_{5}$ & $\mathbf{h}_{5}$ & $\rho_{5 \mathrm{r}}$ & $\rho_{4}$ \\
\hline$\rho_{6}$ & $\mathbf{h}_{6}$ & & $\rho_{5}$ \\
\hline
\end{tabular}

$\mathbf{a}$

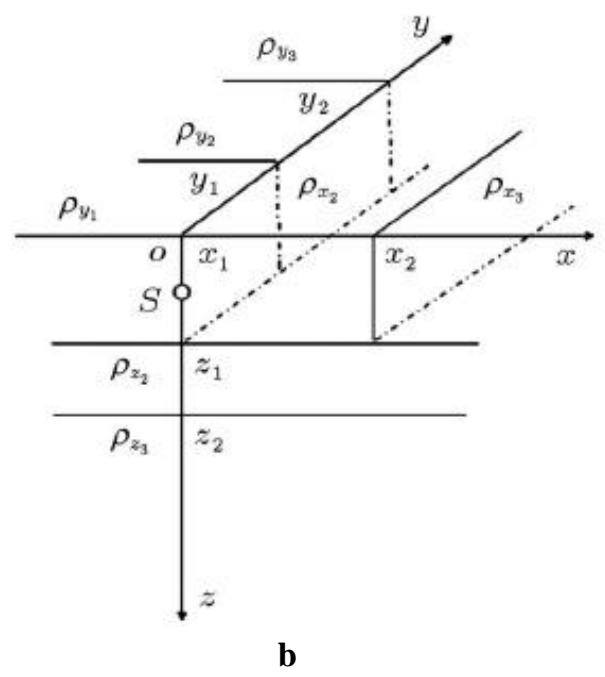

Figure 2. Complex earth resistivity model concerning resistivity lateral change

\section{Ground surface potential model DC around ground electrode}

Grounding current from electrode formed a constant DC current field. The differential equations of the current field can be represented as follows (Eqs. 1 and 2):

$$
\begin{gathered}
\nabla \times \vec{E}=0 \\
\nabla \cdot \vec{J}=-\frac{\partial \rho}{\partial t}
\end{gathered}
$$

Auxiliary equation is (Eqs. 3 and 4):

$$
\begin{aligned}
\vec{J} & =\sigma \vec{E} \\
\vec{E} & =-\nabla V
\end{aligned}
$$


where, $E$ is electric field intensity $(\mathrm{V} / \mathrm{m}), J$ is current density $(\mathrm{A} / \mathrm{m} 2), \rho$ is charge density $(\mathrm{C} / \mathrm{m} 3), \sigma$ is conductivity $(\mathrm{S} / \mathrm{m})$, and $V$ is electric potential $(\mathrm{V})$.

In the field except the current source, the equation $(E q .5)$ of the current field can be expressed as:

$$
\nabla^{2} \cdot V=0
$$

In this paper, the finite element software Ansys is proposed to calculate the surface potential distribution of Jinsi grounding electrode. Based on the three-dimensional composite Earth resistivity model established above, the lateral variation of Earth resistivity should be considered when analyzing the influence mechanism of earth resistivity lateral change on ground surface potential. Three-dimensional problem is transferred into two-dimensional finite element problem. Based on the measured resistivity lateral difference type, to solve the surface potential by axisymmetric analysis with 2D Quad 230 unit, decouple network, input load data and boundary condition (Birchfield et al., 2016; Zulkapli et al., 2018).

External boundary condition (Eq. 6) is:

$$
V=0
$$

At the air interface (Eq. 7):

$$
\frac{d V}{d n}=0
$$

where $\mathrm{n}$ is exterior normal direction (Eqs. 8 and 9), and resistivity adjacent soil interface can be obtained:

$$
\begin{gathered}
V_{i}=V_{j} \\
\frac{1}{\rho_{i}} \frac{d V_{i}}{d n}=\frac{1}{\rho_{j}} \frac{d V_{j}}{d n}
\end{gathered}
$$

The earth surface potential affects up to dozens of $\mathrm{km}$ or greater (Harrison and Anderson, 2016; Barsainya and Rawat, 2017; Rezaei-Zare et al., 2016; Boteler and Bradley, 2016; Pan et al., 2016; Boteler and Pirjola, 1998; Viljanen et al., 2004; Baharuddin and Samsudin, 2018). Since the rated earth current is $5000 \mathrm{~A}$, this paper selected $150 \mathrm{~km}$ as the distance between grounding electrode and 0 potential boundary. Moreover, the Jinsi grounding electrode is double-ring body structure. The polar ring is $1140 \mathrm{~m}$ in the east-west direction, $480 \mathrm{~m}$ in the north and south, $3.5 \mathrm{~m}$ in depth and $0.326 \Omega$ in the grounding resistance. Because the size of the grounding electrode is far less than the influence range of its surface potential, treat the grounding electrode to a point power supply (Zhu and Overbye, 2015; Prabhakaran and Raj, 2018).

Select the rectangular coordinate system, $\mathrm{x}$ refers to the north, $\mathrm{y}$ refers to the East, $\mathrm{z}$ is vertical to ground. The model is shown in Figure 3. In Figure 3, six boundary interfaces for the rectangular structure of the earth model are shown. The arrow reflects a possible flow of the grounding current at the inner and side boundary of the earth conductor. The lateral difference of resistivity may exist inside the conductor, thus 
changing the flow direction of the grounding current to the earth (Zhang et al., 2018). The truncated boundary is selected far away from the zone of resistivity sudden change. It is considered that there is no lateral difference, and the grounding current flow into and out of the model horizontally (Lewicki, 2007; Bernabeu, 2015; Barakat et al., 2018).

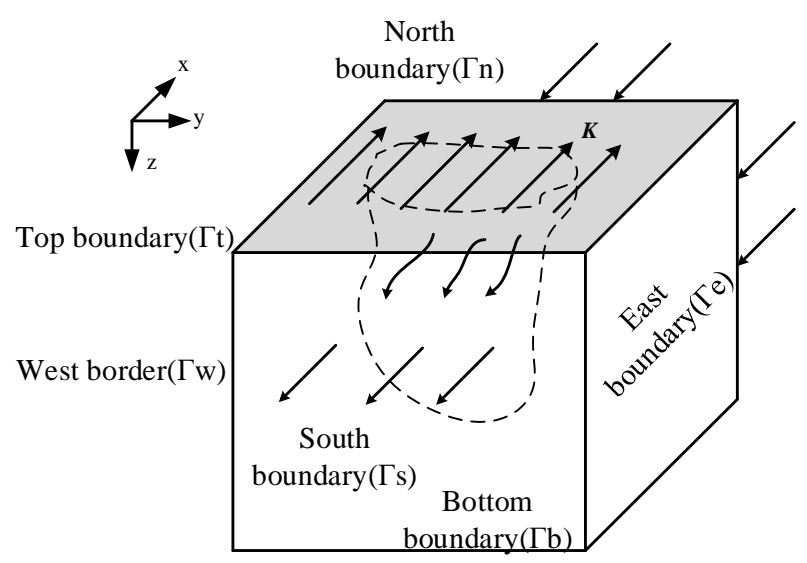

Figure 3. Sketch of earth conductivity model

In this paper, the type of earth resistivity lateral difference should be considered, when analyzing the mechanism of the influence of lateral variation of earth resistivity on ground electrode. According to the resistivity lateral difference type from the experiment, parameters as shown in Table 2. In Table 2, the scheme 1 4 simulate 4 kinds of fracture situations, because the earth resistivity is generally less than $200 \Omega \bullet \mathrm{m}$ in the fracture area, the value here is $150 \Omega \cdot \mathrm{m}$ (Guo et al., 2017). The scheme 5 8 simulate the high and low resistance of surface layer, and the values of shallow-layer high resistance is $1000 \Omega \bullet \mathrm{m}$ and $5000 \Omega \bullet \mathrm{m}$.

Table 2. Parameter scenarios to simulate different soil resistivity lateral changes

\begin{tabular}{c|c|c|c|c|c|c|c|c}
\hline Scheme & $\mathbf{1}$ & $\mathbf{2}$ & $\mathbf{3}$ & $\mathbf{4}$ & $\mathbf{5}$ & $\mathbf{6}$ & $\mathbf{7}$ & $\mathbf{8}$ \\
\hline $\mathrm{D}(\mathrm{m})$ & 800 & 800 & 5000 & 800 & 800 & 800 & 800 & 5000 \\
$\mathrm{~L}(\mathrm{~m})$ & 200 & 200 & 200 & 1000 & 1000 & 1000 & 2000 & 1000 \\
$\rho_{1 \mathrm{r}}(\Omega \cdot \mathrm{m})$ & 150 & 150 & 150 & 150 & 1000 & 5000 & 1000 & 1000 \\
$\rho_{2 \mathrm{r}}(\Omega \cdot \mathrm{m})$ & 150 & 150 & 150 & 150 & 1000 & 5000 & 1000 & 1000 \\
$\rho_{3 \mathrm{r}}(\Omega \cdot \mathrm{m})$ & 150 & 150 & 150 & 150 & 2500 & 2500 & 2500 & 2500 \\
$\rho_{4 \mathrm{r}}(\Omega \cdot \mathrm{m})$ & 150 & 150 & 150 & 150 & 400 & 400 & 400 & 400 \\
\hline
\end{tabular}

\section{Results and discussion}

\section{Analysis of the influence of the lateral variation of earth resistivity on the surface potential}

In this paper, two kinds of Earth resistivity models are proposed, and by using Ansys, the distribution of surface potential of the Jinsi grounding electrode is calculated, based on the 8 scenarios of earth resistivity lateral variation. The results are shown in Figures 4 and 5. In Figures 4 and 5, (a) is the potential distribution within $50 \mathrm{~km}$. In 
order to observe the difference of local potential distribution and its influence, (b) is the enlarged display of the surface potential distribution change near the place where the earth resistivity lateral change happens, and (b) is corresponded to the calculated result in (a). In the figure, the curve " 0 " corresponds to the surface potential distribution in the horizontal homogeneous layered earth resistivity model, and the other curves correspond to the resistivity lateral change plans (Table 2). In the scheme 1 4, the surface potential distribution near the Jinsi ground electrode are shown in Figure 4.

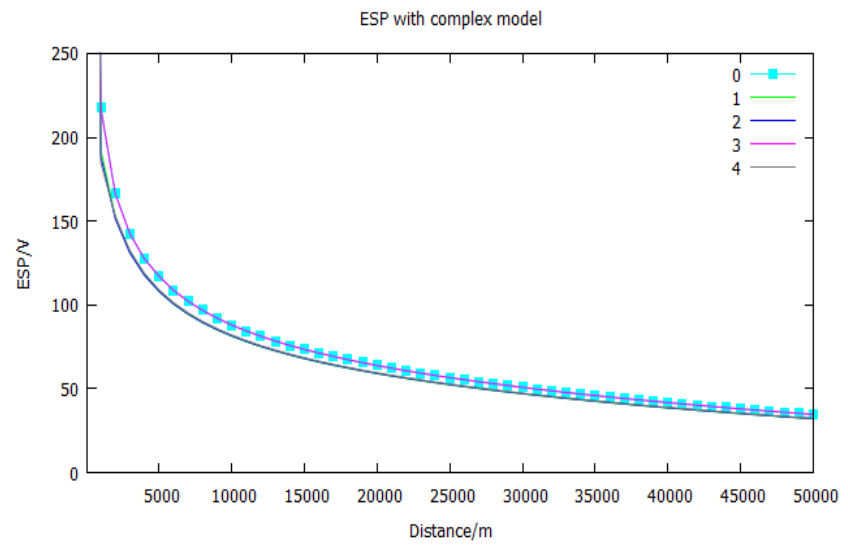

a

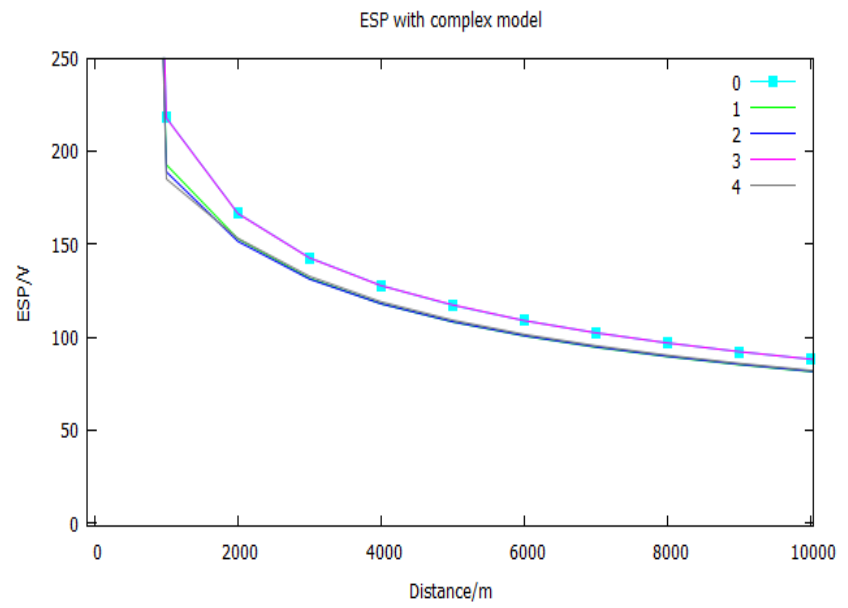

b

Figure 4. Earth conductivity model ESP around Jinsi electrode under resistivity lateral change scenarios $1-4$

As Figure $4 a$ shows the surface potential from the grounding electrode to the fracture interface is overall reduction. Compared with the curve 0 , the surface potential of the curve 1 is obviously reduced, and the curve 3 is almost coincided with the curve 0 . Because the curve 1 is fractured at $800 \mathrm{~m}$, the curve 3 is fractured at $5000 \mathrm{~m}$. The rest of the parameters are the same. This indicates that the closer the fracture interface to the ground electrode, the more significant lateral resistivity change effects on the surface potential. And the fracture in a far position has little effect on the earth surface potential. Moreover, the depth or width parameters among the 3 types of breakages shown in the curves 1,2 , and 4 are different. But the location of the fracture is $800 \mathrm{~m}$, and the surface 
potential of the 3 types are similar. This shows that the distance between the fracture interface and the ground electrode has a greater influence on the surface potential distribution than the depth and width.

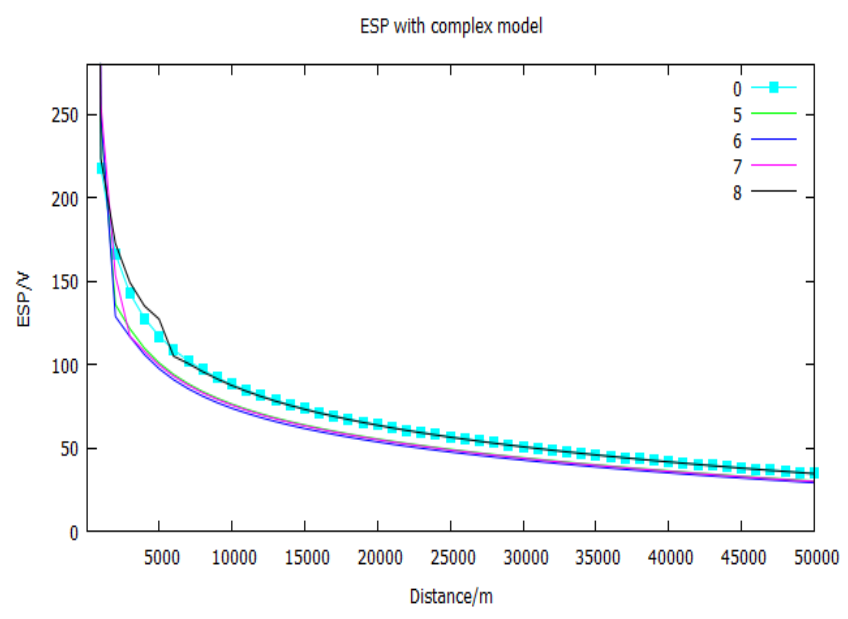

$\mathbf{a}$

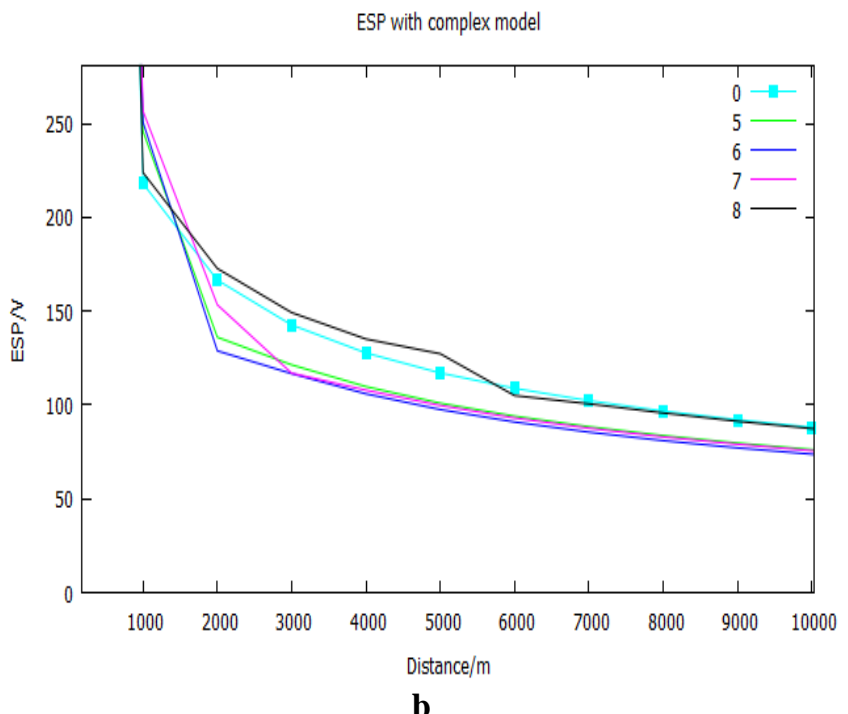

Figure 5. ESP around Jinsi electrode under resistivity lateral change scenarios 5-8 (b)

Near the fracture position, the surface potential dropping of the curves 1,2 , and 4 are different (Fig. 4b). The curve 4 is lower than the curve 1 . This indicates that the greater the width of the fracture, the greater the decrease of the surface potential caused by the influence. The curve 2 is lower than the curve 1 . This indicates that the deeper the depth of the fracture is, the greater the decrease of the surface potential caused by its influence.

In the earth resistivity lateral variation case 5-8, the surface potential distribution around the Jinsi grounding electrode is shown in Figure 5.

Comparing with the horizontal homogeneous layered situations, when considering the resistivity lateral variation caused by the high and low resistance mixture in the surface layer, in front of the high resistance area, the surface potential rises (Fig. 5a). 
And behind the high resistance area, the surface potential drops, and the surface potential drops significantly in the area with high resistance. Comparing with the width and resistivity of the high resistance area, the distance between the interface and the grounding electrode has a greater influence on the surface potential.

In curves 5, 6 and 7, surface potential from the front section of the curve near the high resistance region are different. The surface potential uplift of the front section of the curve 6 is slightly higher than that of the curve 5 (Fig. $5 b$ ). The surface potential behind the high resistance region is slightly lower than that of the curve 5. The higher resistance in high resistance area, the greater the surface potential drops, and the greater the influence on the overall surface potential distribution. Comparing the curves 5 and 7, it can be seen that the greater the width of the high resistance region is, the greater the surface potential drops in the region, and the greater the effect on the overall surface potential. It is noteworthy that the contrast curves 8 and 0 can be seen, when the surface layer high resistance area is far from the grounding electrode, although the surface potential distribution of the high resistance area will not be significantly affected, there will still be obvious surface potential rise in front of the interface, and intensify the surface potential drop in the surface layer high resistance area. Compared with the curve 0 , the surface potential drop between 5 and $6 \mathrm{~km}$ in the curve 8 is $14 \mathrm{~V}$.

\section{The effect of Lateral change of earth resistivity on the intensification of magnetic bias current}

The results of the above calculation and analysis show that, the lateral change of the earth resistivity will cause a significant change in the surface potential around the grounding electrode. Considering the influence of the grounding current, the DC bias current of the nearby power grid is directly affected by the surface potential distribution (Liu et al., 2016). Therefore, it is necessary to investigate the influence of the potential distribution change on the magnetic current of the nearby power grid. Taking case 8 in Table 2 as an example, and the analysis shows that comparing with the earth resistivity homogeneous stratified model, the intensification of lateral resistivity variation on the bias current of the power grid.

\section{Power grid model and parameters}

Since there is no accurate earth resistivity data of the Jinsi grounding electrode at present, it is assumed that there is a power grid containing four $500 \mathrm{kV}$ substations, and the substations distribute along the grounding electrode, numbered respectively with $\mathrm{A}, \mathrm{B}, \mathrm{C}$ and $\mathrm{D}$. The distances of each transformer to the ground electrode are 5 $\mathrm{km}, 10 \mathrm{~km}, 15 \mathrm{~km}$ and $20 \mathrm{~km}$. Two sets of single-phase autotransformer are used in each substations. The high voltage and middle voltage windings of the transformer are $0.238 \Omega$ and $0.097 \Omega$. The grounding resistance of the substation is $0.2 \Omega$. The transmission lines between the substations are four split conductors. The single phase DC resistance of the wire is $0.0187 \Omega / \mathrm{km}$. Its equivalent DC circuit is shown in Figure 6. DC is the neutral grounding equivalent DC potential of the surrounding AC substations under the influence of DC grounding current from grounding electrode (Babazadeh et al., 2017; Shetye and Overbye, 2015; Rezaei-Zare, 2015; Kovan and De Leon, 2016). 


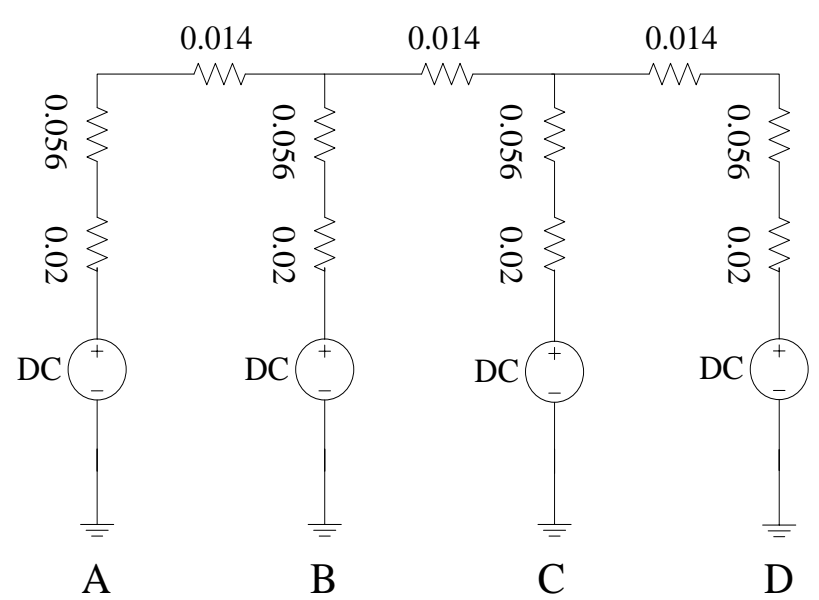

Figure 6. DC bias circuit of the AC network

\section{Calculation results and analysis}

According to the comparative analysis above, the surface potential distribution is calculated by selecting the earth resistivity parameters from scheme 01 and 8 in Table 2 . The surface potential calculation results of each substation are shown in Table 3 (Aboura and Touhami, 2017; Marti and Yin, 2015).

Table 3. ESP distributions under two scenarios $(V)$

\begin{tabular}{l|c|c|c|c}
\hline Distance & $\mathbf{5} \mathbf{~ k m}$ & $\mathbf{1 0} \mathbf{~ k m}$ & $\mathbf{1 5} \mathbf{~ k m}$ & $\mathbf{2 0} \mathbf{~ k m}$ \\
\hline Scheme1 & 117.01 & 88.039 & 73.465 & 63.840 \\
Scheme8 & 127.22 & 87.387 & 73.086 & 63.554 \\
\hline
\end{tabular}

By using the node voltage method, the DC bias current of the transformer in the AC network from Figure 6 is calculated according to the earth surface potential corresponding to the two cases in Table 3. The result of the calculation is shown in Table 4. The positive value indicates the current flows from the earth to the neutral point (Girgis and Vedante, 2015; Rezaei-Zare, 2015).

Table 4. DC bias currents in substations (A)

\begin{tabular}{c|c|c|c|c}
\hline Transformer substation & A & B & C & D \\
\hline Scheme1 & 113.74 & 6.80 & -43.54 & -76.93 \\
Scheme8 & 143.17 & -4.60 & -52.89 & -85.45 \\
\hline
\end{tabular}

The results of the calculation in Table 4 show that, comparing with the horizontal homogeneous layered earth resistivity model, the change of surface potential distribution caused by the high resistance of surface layer between 5 and $6 \mathrm{~km}$ from the grounding electrode. It leads to the bias current increase of some substations in the power grid. Influenced by it, the bias current of substation A, C and D are obviously increased, and the growth rates are $25.9 \%, 21.5 \%$ and $11.1 \%$. 
It can be seen that the change of surface potential distribution caused by lateral variation of earth resistivity will significantly affect the DC bias current level across the grid. However, the surface layer high resistance area is located between substation A and $\mathrm{B}$, it is the horizontal changing area, the potential difference between the two sides of the substation is increased. And the bias current will flow across the entire power gird, this surface potential distribution change will cause the bias current increase of distant substation C and D (Wu et al., 2014; Gilbert, 2015; Boteler, 2015; Kwon et al., 2017; Zhou et al., 2016).

\section{Conclusions}

In this paper, a composite model of earth resistivity considering lateral variation is established. The influence mechanism of the earth resistivity lateral variation on the surface potential is analyzed. It is revealed that the earth resistivity measurement is not elaborate and the data are inaccurate during the site selection and impact assessment of the grounding electrode at present. The conclusions are as follows:

(1) When calculating surface potential caused by grounding current of earth electrode, comparing with calculation results from the horizontal homogeneous layered earth resistivity model, the resistivity lateral change caused by the earth fracture and high and low resistance mixture of surface conducting layer, will significantly affect the scale and distribution of surface potential. The scale of its influence is most affected by the distance between the lateral variation interface to the grounding electrode, The influence of distant fracture can be neglected, but far from the shallow high resistance region will have a greater potential drop in the region, the front curve of ground electric potential rise significantly, and it can not be neglected in the surface potential distribution calculation.

(2) In the calculation of DC bias, the accurate calculation of ESP is the key, and the calculation shows that the variation of ground potential caused by lateral variation of earth resistivity will increase the bias current of the entire power grid when the nearby power grid goes through the lateral resistivity variation area. And because the bias current will circulate in the grid, the change of ground potential in local area will cause the increase of the bias current in a larger region, and if the comprehensive value horizontal homogeneous layered earth resistivity model is adopted, the large error will appear, and the surface layer high resistance at $5 \mathrm{~km}$ in the example will cause the substation bias estimated value to be $25.9 \%$ lower.

(3) Because of the lateral variation of the resistivity at a distance can also cause a significant change in the surface potential distribution, which affects the magnetic current level of the surrounding grid, considering that the distance between the boundary surface and the grounding electrode is the primary influencing factor, and the lateral variation of the $5 \mathrm{~km}$ outside the electrode site can still make a large error in the estimation of the bias current. So at present, the resistivity measurement in the range of the grounding electrode location can not satisfy the requirement of the bias current estimation, and the range of the resistivity measurement should be considered in the siting stage of the grounding pole. The lateral variation of earth resistivity has a great effect on the surface potential distribution, and its scale is related to the range of fracture width, depth, lateral variation, distance to grounding electrode and the level of resistivity change. 
In addition, due to the analysis of the influence mechanism of earth resistivity lateral variation on surface potential, only considering the two-dimensional resistivity model of the Earth, the three-dimensional problem is converted into two-dimensional finite element analysis, and the actual earth resistivity is changed in the three-dimensional land space, which may have a greater effect on the distribution of ground potential. This impact needs to be further studied.

Acknowledgements. This work was supported by National Key R\&D Program of China (2016YFC0800100); Project Supported by National Natural Science Foundation of China (51677068, 51577060).

\section{REFERENCES}

[1] Aboura, F., Touhami, O. (2017): Effect of the GICs on magnetic saturation of asymmetric three-phase transformer. - IET Electric Power Applications 11(7): 1306-1314.

[2] Arslan, C. H., Sattar, A., Cuong, D. M., Khan, F. U. H., Nasir, A., Bakhat, Z., Ilyas, F. (2018): Study of spatial and temporal variability of arsenic in groundwater due to drain by using GIS. - Earth Sciences Pakistan 2(2): 22-24.

[3] Austin, O. E., Ebuka, A. O., Zanders, A. C. C., Joseph, I. N. (2018): Seismic analysis of the transgressive systems tracts (TSTS) of the Niger Delta. - Earth Sciences Malaysia 2(2): 16-19.

[4] Babazadeh, D., Muthukrishnan, A., Mitra, P. (2017): Selection of DC voltage controlling station in an HVDC grid. - Electric Power Systems Research 144: 224-232.

[5] Baharuddin, D., Samsudin, M. D. M. (2018): Effect of Ph and moisture content on current density of impressed current cathodic protection: response surface methodology study. - Environment \& Ecosystem Science 2(2): 15-19.

[6] Barakat, A., Khellouk, R., Jazouli, A. E., Touhami, F., Nadem, S. (2018): Monitoring of forest cover dynamics in eastern area of Béni-Mellal Province using ASTER and Sentinel-2A multispectral data. - Geology, Ecology, and Landscapes 2(3): 203-215.

[7] Barsainya, R., Rawat, T. K. (2017): Novel realization of GIC based wave digital filters using Al-Alaoui transform. - Alexandria Engineering Journal. DOI: 10.1016/j.aej.2017.03.010.

[8] Bernabeu, E. E. (2015): Single-Phase transformer harmonics produced during geomagnetic disturbances: theory, modeling, and monitoring. - IEEE Transactions on Power Delivery 30(3): 1323-1330.

[9] Birchfield, A. B., Gegner, K. M., Xu, T. (2016): Statistical considerations in the creation of realistic synthetic power grids for geomagnetic disturbance studies. - IEEE Transactions on Power Systems 99: 1-1.

[10] Boteler, D. H. (2015): The evolution of Québec earth models used to model geomagnetically induced currents. - IEEE Transactions on Power Delivery 30(5): 21712178.

[11] Boteler, D. H., Bradley, E. (2016): On the interaction of power transformers and geomagnetically induced currents. - IEEE Transactions on Power Delivery 31(5): 21882195.

[12] Boteler, D. H., Pirjola, R. (1998): The complex-image method for calculating the magnetic and electric fields produced at the surface of the Earth by the auroral electrojet. - Geophysical Journal International 132(1): 31-40.

[13] Choi, D. H., Lee, S. H., Son, G. T. (2018): Planning of HVDC System Applied to Korea Electric Power Grid. - Journal of Electrical Engineering \& Technology 13(1): 105-113. 
[14] Gilbert, J. L. (2015): Simplified techniques for treating the ocean-land interface for geomagnetically induced electric fields. - Electromagnetic Compatibility IEEE Transactions on 57(4): 688-692.

[15] Girgis, R. S., Vedante, K. B. (2015): Impact of GICs on power transformers: overheating is not the real issue. - IEEE Electrification Magazine 3(4): 8-12.

[16] Guo, M., Xue, Y., Gao, Z., Zhang, Y., Dou, G., Li, Y. (2017): Dynamic analysis of a physical SBT memristor-based chaotic circuit. - International Journal of Bifurcation and Chaos 27(13): 1730047.

[17] Harrison, C. W., Anderson, P. I. (2016): Characterization of grain-oriented electrical steels under high DC biased conditions. - IEEE Transactions on Magnetics 52(5): 1-4.

[18] Hussein, A. A., Ali, M. H. (2017): Fuzzy logic controlled variable resistor for suppressing GIC in transformers. - Iet Generation Transmission \& Distribution 11(6): 1494-1501.

[19] Kang, L.; Du, H. L.; Du, X.; Wang, H. T.; Ma, W. L.; Wang, M. L.; Zhang, F. B. (2018): Study on dye wastewater treatment of tunable conductivity solid-waste-based composite cementitious material catalyst. - Desalination and Water Treatment 125: 296-301.

[20] Kasim, S., Hassan, R., Zakaria, Z. (2019): Re-engineering in confinement method. Engineering Heritage Journal 3(1): 18-19.

[21] Kazerooni, M., Zhu, H., Overbye, T. (2016a): Transmission system geomagnetically induced current model validation. - IEEE Transactions on Power Systems 99: 1-1.

[22] Kazerooni, M., Zhu, H., Overbye, T. J. (2016b): Improved modeling of geomagnetically induced currents utilizing derivation techniques for substation grounding resistance. IEEE Transactions on Power Delivery 99: 1-1.

[23] Kovan, B., De Leon, F. (2016): Mitigation of geomagnetically induced currents by neutral switching. - Power Delivery IEEE Transactions on 30(4): 1999-2006.

[24] Kwon, D., Kim, Y., Moon, S. (2017): Modeling of HVDC system to improve estimation of transient DC current and voltages for AC line-to-ground fault - an actual case study in Korea. - Energies 10(10): 1543.

[25] Lewicki, J. (2007): Equivalent circuits of transformers with distorted and asymmetricalcurrents and supply voltages and with regard to magnetizing current. - IEEE International Symposium on Industrial Electronics IEEE Xplore 2: 820-826.

[26] Liu, F. (2018): Rough maximal functions supported by subvarieties on Triebel-Lizorkin spaces. - Revista de la Real Academia de Ciencias Exactas, Físicas y Naturales. Serie A. Matemáticas 112(2): 593-614.

[27] Liu, L. G., Wei, K., Ge, X. N. (2015): GIC in future large-scale power grids: an analysis of the problem. - IEEE Electrification Magazine 3(4): 52-59.

[28] Liu, Y. P., Liu, H. C. (2017): Influence of endurance tests on space charge distribution of $160 \mathrm{kV}$ HVDC XLPE cable. - Journal of Electrical Engineering \& Technology 12(1): 302-309.

[29] Marti, L., Yin, C. (2015): Real-time management of geomagnetic disturbances: Hydro One's eXtreme space weather control room tools. - Electrification Magazine IEEE 3(4): 46-51.

[30] Moon, B. S., Ko, B., Choi, J. S. (2017): The study on the efficient HVDC capacity considering extremely low probability of $765 \mathrm{kV}$ double circuit transmission lines trip. Journal of Electrical Engineering \& Technology 12.

[31] Mousavi, S. A., Bonmann, D. (2017): Analysis of asymmetric magnetization current and reactive power demand of power transformers due to GIC. - Procedia Engineering 202: 264-272.

[32] Okpoli, A. O., Ehinmitan, D. (2019): Geological and lithologigal mapping of part of Igarra Schist belt using integrated geophysical method. - Earth Sciences Pakistan 3(1): 01-09.

[33] Pan, Z., Zhang, L., Wang, X. (2016): HVDC ground return current modeling in AC systems considering mutual resistances. - IEEE Transactions on Power Delivery 31(1): 165-173. 
[34] Prabhakaran, A., Raj, N. J. (2018): Mapping and analysis of tectonic lineaments of Pachamalai hills, Tamil Nadu, India using geospatial technology. - Geology, Ecology, and Landscapes 2(2): 81-103.

[35] Rajput, K., Gupta, A., Arushi (2019): Re-cycle of e-waste in concrete by partial replacement of coarse aggregate. - Engineering Heritage Journal 1(1): 05-08.

[36] Rezaei-Zare, A. (2015a): Reactive power loss versus GIC characteristic of single-phase transformers. - IEEE Transactions on Power Delivery 30(3): 1639-1640.

[37] Rezaei-Zare, A. (2015b): Enhanced transformer model for low- and mid-frequency transients-Part II: validation and simulation results. - IEEE Transactions on Power Delivery 30(1): 316-325.

[38] Rezaei-Zare, A., Marti, L., Narang, A. (2016): Analysis of three-phase transformer response due to GIC using an advanced duality-based model. - IEEE Transactions on Power Delivery 31(5): 2342-2350.

[39] Shetye, K., Overbye, T. (2015): Modeling and analysis of GMD effects on power systems: an overview of the impact on large-scale power systems. - IEEE Electrification Magazine 3(4): 13-21.

[40] Viljanen, A., Pulkkinen, A., Amm, O. (2004): Fast computation of the geoelectric field using the method of elementary current systems and planar Earth models. - Annales Geophysicae 22(1): 101-113.

[41] Wali, E., Phil-Eze, P. O., Nwankwoala, H. O. (2018): Saltwater-freshwater wetland ecosystem and urban land use change in Port Harcourt Metropolis, Nigeria. - Earth Sciences Malaysia 2(1): 01-07.

[42] Wang, J., Gao, C., Duan, X. (2015): Multi-field coupling simulation and experimental study on transformer vibration caused by DC bias. - Journal of Electrical Engineering \& Technology 10(1): 176-187.

[43] Wei-Li, W. U., Liu, L. G. (2013): Long-distance transmission system voltage sensitivity research of geoelectric field due to magnetic storm. - Science Technology \& Engineering 2013(16).

[44] Wu, W. L., Liu, L. G., Liu, C. M. (2014): Voltage stability in a long-distance power transmission system impacted by the geoelectric field due to a geomagnetic disturbance. Earth Science Informatics 7(3): 173-185.

[45] Yang, B., Luo, Y., Jeng, D., Feng, J., Huhe, A. (2018): Experimental studies on initiation of current-induced movement of mud. - Applied Ocean Research 80: 220-227.

[46] Zhang, X., Liu, L., Wu, Y., Cui, Y. (2018): Existence of infinitely solutions for a modified nonlinear schrodinger equation via dual approach. - Electronic Journal of Differential Equations 147: 1-15.

[47] Zhou, D., Zhang, K., Ravey, A., Gao, F., Miraoui, A. (2016): On-line estimation of lithium polymer batteries state-of-charge using particle filter based data fusion with multi-models approach. - IEEE Transactions on Industry Applications 52(3): 2582-2595.

[48] Zhu, H., Overbye, T. J. (2015): Blocking device placement for mitigating the effects of geomagnetically induced currents. - IEEE Transactions on Power Systems 30(4): 20812089.

[49] Zulkapli, M. F., Rashid, N. M., Sokri, M. N. M., Nasri, N. (2018): Study on optical properties of graphene-TiO2 nanocomposite as photoanodes layer in dye sensitized solar cell (DSSC). - Environment \& Ecosystem Science 2(2): 39-41. 